\title{
Mídia e mercado: mediações na construção de sentidos do consumo das "roupas de marca"
}

Ana Lúcia de Castro'

\section{Resumo}

Tomando como recorte empírico um bairro localizado na periferia de Santo André, município da Grande São Paulo, este artigo busca contribuir para a compreensão da dimensão simbólica dos bens de consumo e os sentidos a eles atribuídos em contextos periféricos. Abordamos, especificamente, a relação com o universo das grifes, ou, nas palavras dos interlocutores, das "roupas de marca", partindo de conversas realizadas durante um grupo focal realizado com jovens (de 18 a 24 anos), além de alguns trechos de entrevistas individuais e registros de diário em campo. Discute-se, ainda, o papel de guia de orientação cumprido pela mídia, ao difundir estilos de roupas e acessórios, bem como grifes, sobretudo esportivas. Interessa-nos identificar os modos de apropriação e uso, bem como motivações para o consumo - para além das razões de ordem prático-utilitaristas - colocando em discussão a atualidade e pertinência da explicação sociológica hegemônica, que aponta para a lógica da imitação-distinção como principal propulsora para esta prática. (VEBLEN, 1983; SIMMEL, 2006; BOURDIEU, 2007).

Palavras-chave: consumo, mídia, mediações, distinção social, modos de uso.

\section{Introdução}

Este artigo busca contribuir para a compreensão da dimensão simbólica dos bens de consumo e os sentidos a eles atribuídos em contextos periféricos ${ }^{2}$, constituídos por grupos de baixa renda. Discute-se, ainda, o

I Professora do Programa de Pós-graduação em Ciências Sociais - FLCAr/UNESP, campus Araraquara. Email: castroanalucia75@gmail.com.

2 Neste trabalho, a noção de periferia carrega tanto o sentido geográfico como socioeconômico. Os interlocutores da pesquisa residem em um bairro constituído por núcleos de favelas em Santo André, Grande São Paulo, e segundo dados levantados pela CDHU (Companhia de Desenvolvimento habitacional Urbano), o percentual de domicílios com renda familiar per capita mensal de até meio salário mínimo é bem maior do que a média nacional (CASTRO, 20I6).

Direito autoral e licença de uso: Este artigo está licenciado sob uma Licença Creative Commons. Com essa licença você pode compartilhar, adaptar, para qualquer fim, desde que atribua a autoria da obra, forneça um link para a licença, e indicar se foram feitas alterações. 
papel de guia de orientação, cumprido pela mídia, ao difundir estilos de roupas e acessórios, bem como grifes, sobretudo esportivas. Interessa-nos identificar motivaçóes para o consumo - para além das razóes de ordem prático-utilitaristas - colocando em discussáo a atualidade e pertinência da explicação sociológica hegemônica, que aponta para a lógica da imitaçãodistinção como principal propulsora para esta prática (VEBLEN, 1983; SIMMEL, 2006; BOURDIEU, 2007).

A despeito do movimento teórico representado pelos estudos culturais ingleses - que apresentou uma perspectiva dissonante da então hegemônica, representada, paradigmaticamente, pela escola de Frankfurt - os temas do consumo, assim como do lazer e da cultura de massa, ficaram relegados à condição secundária, entendidos como questóes menos importantes, pelas análises das ciências sociais de maior repercussão.

Dentre as contribuiçóes dos teóricos ligados aos cultural studies - que têm como expoentes as reflexóes de Raymond Williams, Richard Hoggart e Edward Palmer Thompson - vale destacar, pela proximidade às preocupaçóes desta pesquisa, o pioneiro trabalho de Hoggart (1973), primeiro diretor do Centre for contemporay cultural studies (CCCS), fundado em 1964 na Universidade de Birmingham. De maneira original, o autor toma como objeto de discussão "as formas de uso e apropriação" de revistas voltadas às mulheres de classes populares na Inglaterra dos anos 1950, inaugurando uma perspectiva analítica que considera a recepção dos meios de comunicação de massa e o consumo como esferas de produção de sentido e não apenas de reprodução da lógica dominante,

Contudo, apesar do refinamento do debate teórico propiciado pelos estudos culturais ingleses, o tema do consumo permaneceu, nas ciências sociais, relegado a um segundo plano (DUARTE, 2010) e associado à futilidade, sendo tratado, via de regra, como fenômeno a ser moralmente condenável - ou por contribuir para a reproduçáo da ideologia dominante, anestesiando as massas, na esteira da crítica dos frankfurtianos Adorno e Horkheimer (1985), ou por contribuir para a destruição do planeta, perspectiva crítica dos ecologistas, como demonstra Miller (2004).

Além de difundir uma visão moralista - demonizadora e condenatória - do consumo como prática social, como demonstra Miller (2004), 
os estudos existentes raramente enfocam as classes menos abastadas, por pressuporem, em geral, que o fenômeno náo diz respeito a estas (SCALCO; PINHEIRO MACHADO, 2010). Embora conte com uma tradição de estudos voltados às classes trabalhadoras e populares (DUARTE, 1986; FONSECA, 2000; SARTI, 1996), a produção brasileira conta com poucos trabalhos voltados ao estudo do consumo entre essas classes, reforçando a ideia de que a vinculação entre consumo e classes populares não era, até bem recentemente, presente no debate das ciências sociais, visto que, geralmente, partia do pressuposto de que o consumo do trabalhador de baixa renda estaria restrito ao rol dos bens entendidos como "de primeira necessidade”.

A colocação do binômio consumo-classes populares na agenda do debate é decorrente de mudanças experimentadas, tanto no plano teórico, como na dinâmica da estrutura social brasileira. No tocante ao primeiro plano referido, notamos que ganhou força, no debate sobre consumo, uma perspectiva analítica socioantropológica acerca da circulação e apropriação de bens que enfatiza a sua dimensão simbólica, afastando-se das explicaçóes vigentes, marcadas pelo seu caráter moralista e/ou pautadas por dualismos e polarizaçóes (CASTRO, 2016).

Como já indicado, a visão moralista e dual do consumo encontra um marco significativo na reflexão de Adorno e Horkheimer (1985), que pensam o indivíduo "engolfado pelo consumo" na sociedade industrial de massa. O consumo assumiria, nesta visão, o papel de anestesiar as consciências. Pensada como espécie de engodo, a prática do consumo promoveria apenas a reprodução social, propiciando um pseudoprazer e atendendo aos interesses dominantes ao desviar os indivíduos de suas "reais preocupaçóes".

Embora esta perspectiva teórica muito contribua para a compreensão de mecanismos de dominação instaurados na esfera da produção de mercadorias, ela acaba por limitar a compreensão, por náo considerar as mediaçóes entre os polos da produção e do consumo e anular este segundo (MARTÍN-BARBERO, 1997; CANCLINI, 1997).

A crítica à perspectiva extremamente dual que marca as ciências sociais e humanas pode ser localizada, também, nas reflexóes de Appadurai (2008), para quem, ao se analisar as práticas de consumo, é preciso: 
[...] olhar as mercadorias como coisas. Olhar para o potencial mercantil de todas as coisas, em vez de achar a distinção entre mercadorias e coisas. Romper categoricamente com a visão marxista dominada pela perspectiva da produção, passando pela troca, distribuição, até o consumo. (APPADURAI, 2008).

Outro aspecto importante a ser destacado na crítica contemporânea acerca da visão moralista e dual do consumo é indicado por Daniel Miller (2004) cujo estudo aponta para a ideia de que "o consumo sob o capitalismo não é apenas consumo capitalista”. Assim como Appadurai (2008), o autor nega o pressuposto de que estaríamos diante de sujeitos cegos e amarrados à sociedade de consumo, movidos apenas pelo cálculo interessado e por impulsos materialistas, apontando para a agência de sujeitos que encontram prazer, reforçam vínculos e constroem relaçôes ao consumir.

Em etnografia realizada em camelódromos no Rio de Janeiro e em Porto Alegre, Scalco e Pinheiro-Machado (2010, p. 3-4) retomam o pressuposto de Miller de que, ao contrário de desumanizar, a prática do consumo aproxima as pessoas, pois "quanto mais próxima nossa relaçáo como os objetos, mais próxima nossa relação com os humanos [...]" e as pessoas "[...] compram porque se relacionam e se relacionam porque compram", reafirmando a noçáo de que o ato da compra situa-se entre "[...] o individual e o social, ou seja, como uma ação relacional, cuja escolha está diretamente vinculada a uma rede afetiva e singular".

Esta perspectiva analítica, portanto, enfatiza os “aspectos simbólicos das trocas e apropriaçóes dos objetos”, sendo caudatária de uma longa tradição, iniciada com Marcel Mauss (2003), em seu clássico "Ensaio sobre a dádiva”, passando por Jean Baudrillard (1995), Marshall Sahlins (2004), Mary Douglas e Baron Isherwood (2004) e, mais recentemente, Arjun Appadurai (2008) e Daniel Miller (2002).

Como já apontado em trabalho anterior,

A proposição de uma experiência etnográfica que prevê o "encontro empático" com os consumidores, busca, de um lado, contribuir ao esforço de restituir a dimensão cultural de nossa sociedade, em geral tratada apenas como economia (APPADURAI, 2008), numa abordagem da cultura material por meio das nuanças da imersão etnográfica, tal como desenvolvida por Miller (2002); e de outro lado, colaborar para a construção de uma perspectiva analítica que alargue a corriqueira continuidade das obras de Veblen ( 1983) e Bourdieu 
(2007), tão presentes nas ciências sociais, ora tomando-se exemplos extremos de consumo conspícuo como caracterização de todo e qualquer consumo, ora indicando-se a instrumentalização de bens de consumo nas estratégias de distinção. (CASTRO, 2016, p. 32).

Enquanto este debate teórico se consolidava, experimentávamos, no Brasil, mudanças significativas em suas relaçôes sociais, produto das políticas de inclusão social implementadas, sobretudo no governo Lula, e que tiveram sua implantação viabilizada com a estabilização da economia, promovida pelo Plano Real. Considerando que "classe" é uma categoria analítica que extrapola a dimensão estritamente econômica e envolve valores (ethos) e práticas (modos de uso), não podemos concordar, evidentemente, com a ideia de que se tratava do surgimento de uma "nova classe média", como anunciado por setores do governo federal à época, mas é preciso destacar o nada desprezível contingente de pessoas que na primeira década dos anos 2000 passou a ter acesso, de maneira inédita, um mercado de bens de consumo do qual estava anteriormente alijado.

A controvérsia gerada à época originou-se da classificação proposta por alguns intelectuais e técnicos ligados ao governo federal, a qual propunha que deveriam ser considerados como membros da classe média os indivíduos que viviam em famílias com renda per capita mensal entre 291,00 e $1.019,00$ reais e tivessem pouca probabilidade de passar, futuramente, à condição de pobre (NERI, 2011). Embora frágil do ponto de vista conceitual, esta classificação proposta pelos técnicos do governo apontava para um fenômeno novo: entre 2004 e 2010, 32 milhões foram incluídos na condição de consumidores, contingente de pessoas que alçaram à condição de "classe média", representando $53 \%$ da população, enquanto pelo mesmo critério de classificação apenas 28\% estavam nesta condição em 2002 (BRASIL, 2012). ${ }^{3}$

Vale lembrar que, ao lado do surgimento deste contingente de "novos consumidores", que foi denominado de "nova classe média", outras mudanças estruturais contribuíram para uma nova conformação da sociedade brasileira, tais como o crescimento da taxa de urbanização $(84,3 \%$ em

3 Conforme estudo divulgado em setembro de 2012 pela Secretaria de Assuntos Estratégicos da Presidência da República, disponível em: www.sae.gov.br/wp-content/uploads/Cartilha-Vozes-Classe-Media.pdf. 
2010 , contra $45,1 \%$ em 1960$)$, a queda na taxa de fecundidade $(1,86 \%$ em 2010 e 6,21\% em 1950) ALVES; CAVENAGHI, 2012) ${ }^{4}$ e aumento do emprego no setor serviços (57,6\% em 2008 e 22,5\% em 1950) (BRASIL, 2011). ${ }^{5}$

São inegáveis os desdobramentos positivos das políticas de inclusão social, tais como a melhoria da renda dos mais pobres e a colocação de perspectivas e possibilidades nunca antes experimentadas por setores economicamente mais fragilizados da população, contudo não podemos assumir uma noção de classe média que considere, apenas, o fator renda. Vale lembrar as reflexôes de Souza (2010), que apontam que nos grupos com baixo capital cultural e herança de capital econômico na maior parte das vezes nula, as conquistas de melhores condições de vida e algum tipo de distinção social sustenta-se na família estruturada, que se configura como uma espécie de capital familiar, composto pela transmissão de exemplos e valores do trabalho duro e continuado, ainda que em condiçóes muito adversas.

Interessa-nos, nesta reflexão, contribuir para a compreensão acerca do impacto deste processo de ampliação do acesso ao consumo nas relaçôes entre os grupos de baixo capital econômico e cultural (BOURDIEU, 2007) e nas suas práticas de consumo. Vislumbramos, neste sentido, contribuir para a compreensão dos sentidos do consumo dentre este "novo grupo de consumidores”, tomando como recorte empírico o Jardim Santo André, bairro da periferia do município de Santo André, Grande São Paulo, onde realizamos trabalho de campo, envolvendo observaçóes, entrevistas e grupos focais, durante os anos de 2014 e 2015.6 Neste artigo abordarei - além de algumas entrevistas individuais e registros em diário de campo - principalmente os conteúdos de um grupo focal realizado com oito jovens de 18 a 24 anos, para enfocar, especificamente, o tema relativo ao consumo de "grifes" ou de "bens de marca", como chamados pelos interlocutores. A realização do grupo focal demonstrou-se muito profícua. A experiência da entrevista em grupo promoveu a desinibição dos envolvidos, que foram

\footnotetext{
4 Disponível em: http://www.ie.ufrj.br/aparte/pdfs/tendencias_demograficas_e_de_familia_24ago I2.pdf.

5 Disponivel em: http://portal.mte.gov.br/data/files/8A7C812D3374524E013389E20D294A08/IPEA_II0804_ comunicadoipea I04.pdf.

6 Maior detalhamento do desenho metodológico da pesquisa em: Castro, 2016.
} 
se "soltando" no decorrer da conversa e, aos poucos, se posicionando sobre os temas tratados.

A técnica do Grupo Focal consiste em reunir, idealmente, um grupo de oito a 15 informantes, um coordenador e um relator ${ }^{7}$. A discussão, conduzida pelo coordenador, é pautada por um roteiro pré-estruturado de questōes e ao relator cabe a tarefa de anotar as impressóes, reaçóes e tudo aquilo que diz respeito ao "não verbalizado". O perfil dos informantes reunidos é definido com critério intencional, em sintonia com os interesses da pesquisa. A vantagem desta técnica é que se foca na exploração de temas específicos, além do que, por ser uma entrevista em grupo, acaba motivando todos os membros a exporem suas ideias, em uma espécie de "conversa", com tom descontraído e informal. $\mathrm{O}$ local em que realizamos a conversa foi a Associação dos moradores do bairro, espaço cedido pela presidente da associação, quem se demonstrou uma interlocutora-chave no decorrer da etnografia, auxiliando no contato e convite dos participantes.

\section{Modos de consumo: "roupas de marca" e sentidos das apropriações}

Desde nossas primeiras incursóes ao bairro, saltou-nos aos olhos os varais improvisados com camisetas estampando grifes conhecidas. A presença das grifes - visíveis nos bonés, tênis e camisetas usados pelos mais jovens - foi reforçando nosso pressuposto de que, a despeito da precariedade das condiçôes de moradia, o consumo destes bens era muito frequente, sobretudo entre os jovens. Outro dado que nos chamou a atenção, nas sondagens exploratórias, foi o grande número de "salóes de beleza", consistindo em pequenos cômodos, muitas vezes com o piso em "terra batida", identificados com placas em materiais improvisados, como papelão ou sobras de autoconstruçáo.

A circulação de produtos de grife em um local marcado por tanta precariedade material foi um dos primeiros achados da pesquisa, que nos levou a perguntas como: quais são os locais de compra mais acessados pelos moradores? Que tipo de relação é mantida com o universo das grifes?

7 Registro meus agradecimentos à, então mestranda, Beatriz Haddad, quem acompanhou parte do trabalho de campo e foi a relatora deste grupo focal. 
Com relação à primeira pergunta, logo se evidenciou que os moradores não saem do município de Santo André e pouco realizam compras de vestuário, principalmente os adultos acima dos 30 anos, que recebem doaçóes de roupas usadas, geralmente dos patróes e patroas, para quem realizam serviços domésticos e reparos na casa. Quando realizam compras, na maior parte das vezes, vão à loja Torra Torra, rede de lojas populares que vende roupas no chamado baciāo, ou seja, peças amontoadas, sem nenhuma organização por modelo, cor ou tamanho. O shopping da cidade é frequentado apenas pelos jovens, os quais, em geral, não vão para comprar, mas apenas para: "ver as vitrines, dar um 'rolê', ou no máximo, tomar um sorvete de casquinha do McDonald's".

Esta forma de apropriação do espaço do shopping permite nos aproximarmos das reflexóes de Douglas e Isherwood (2006) e de Michel de Certeau (1994), que apontam para o consumo como "uso" ou "apropriação". Em um esforço de construir uma noção universal de consumo, cabível a culturas localizadas em qualquer tempo ou espaço, Douglas (2006) o define como: "[...] um uso de posses materiais que está além do comércio e é livre dentro da lei (p. 102)"; e, voltando-se para o entendimento do consumo nas sociedades capitalistas propóe compreendê-lo como "[...] um processo ritual cuja função primária é dar sentido ao fluxo incompleto de acontecimentos e fixar significados públicos” (p. 112).

A prática de ir ao shopping "para ver as vitrines" indica um peculiar modo de consumo, voltado aos espaços e imagens, revelando a possibilidade da realização desta prática sem, necessariamente, a intermediação monetária; trata-se do consumo como experiência, na qual o que se adquire é impalpável ou simbólico. Esta modalidade de consumo decorre do trabalho daqueles denominados por Bourdieu (2007) como "novos intermediários culturais" - são os profissionais de marketing, relaçóes públicas, publicitários, apresentadores de programas de rádio e televisão, jornalistas, comentadores de moda - que promovem a difusão de imagens e referências estilísticas, fornecendo orientação e modelos de conduta, no fluxo global de imagens e repertórios simbólicos característico da cultura mundializada

8 Flávia, 20 anos, estudante do primeiro ano do ensino médio, balconista em lojinha no bairro, durante o grupo focal em dezembro de 2015. 
(APPADURAI, 2004; ORTIZ, 1994), promovendo o fenômeno denominado por Featherstone (1995) de "estetização da vida cotidiana".

É curioso notar que, durante as entrevistas realizadas com os moradores responsáveis por gerir o orçamento doméstico - pais, mães ou avós, em geral - ficou claramente evidenciado que não se preocupam com "roupas de marca" ou com a compra de peças originais, sempre remetendo esta preocupação a "um outro", geralmente mais jovem:

[...] não ligo pra roupas de marca... Só minha filha, que é raridade eu dar as coisas pra ela. Mas, quando dou, ela quer coisa boa, celular de mil reais, essas coisas. [...] Ah, quando eu tenho algum dinheiro, eu vou atrás. Mas pra ela... Eu mesma não sou chegada a marca nenhuma".

Entre uma conversa e outra com os interlocutores adultos, observávamos os jovens, muitas vezes portando tênis, bonés ou camisetas com logos de grifes; e, quando os abordávamos informalmente, demonstravam outra relaçáo com este universo, indicando o desejo de possuir mais roupas e acessórios "de marca", mas a barreira financeira era logo apontada. Foi se evidenciando, durante o trabalho de campo, duas principais formas de aquisição de produtos de grife, a preços acessíveis: os "bazares beneficentes", realizados na sede da Associaçáo de moradores do bairro - quando se comercializa produtos doados, muitos dos quais roupas de marcas consagradas, como Zara e Fórum - e a "feira da madrugada", onde são comercializados produtos em grande parte de origem ilegal e que ocorre clandestinamente em algumas noites de alguns finais de semana. Os locais em que a feira ocorre são variados e sua divulgação é feita discretamente, no "boca a boca", para que não haja intervenção policial.

$\mathrm{Na}$ tentativa de aprofundar um pouco mais a compreensão sobre a relação do grupo com o universo das grifes - pelos interlocutores desta pesquisa identificadas como "roupas de marca" - realizamos um grupo focal composto exclusivamente por jovens, no qual um dos aspectos mais recorrentes nos discursos refere-se ao consumo de produtos originais ou de réplicas, sendo estas últimas preferidas em relação aos produtos "sem marca” e a compra de originais reservada a ocasióes e pessoas especiais.

9 Depoimento de Amélia, estudante da sexta série do ensino fundamental, 34 anos, diarista, moradora dos "predinhos", concedido em entrevista individual, em abril de 2015. 
Chamou-nos atenção a concepção, por parte dos interlocutores no grupo, do que é considerado como "roupa de marca", sendo esta identificada como as roupas das lojas de departamento do shopping da cidade: "roupa de marca é a da C\&A e da Renner". ${ }^{\circ}$ Percebemos que o universo das grifes é muito pouco reconhecido, sendo o que é "de marca" muito pouco identificado. Quando expusemos os logos de grifes mundialmente reconhecidas e prestigiadas, apenas aquelas ligadas ao universo esportivo foram reconhecidas e identificadas pelo nome. Louis Vuitton, por exemplo, era chamada como "aquela da bolsa". O maior reconhecimento dos logotipos das marcas ligadas ao universo esportivo está ligado à sua vinculação aos ídolos, sobretudo do futebol, e sua maior exposição nos meios de comunicação, especialmente, na televisão.

\section{Mídia, Mediações}

A associação entre o universo das grifes, ou das "roupas de marca", e as "celebridades", sobretudo quando encarnam personagens das telenovelas, foi muito evidenciada nos diálogos estabelecidos no grupo focal. Em diversas situaçóes, tais personagens eram citadas para exemplificar o que se buscava afirmar: "eu gosto de um estilo mais clássico, sabe? Como o da Glória Pires nesta novela das nove". No caso, a personagem era uma arquiteta, que utilizava seus poderes sedutores para alcançar o que desejava na telenovela "Babilônia". Durante a exibição da novela, entre março e agosto de 2015, a personagem encarnada pela atriz liderou "a lista de figurinos mais pedidos da Globo" (ZWIPP, 2015)".

E a tomada da personagem como modelo ideal não se refere apenas às roupas, mas também aos acessórios e penteados:

Glória Pires vem ditando tendência na pele da vilã e "devoradora de homens" na novela Babilônia, da TV Globo. No mês de abril, o esmalte vermelho usado pela atriz ficou no topo do ranking da lista de itens mais pedidos pelos telespectadores da trama. O corte de cabelo

I0 Flávia, estudante do primeiro ano do ensino médio, 20 anos, balconista em loja do bairro, moradora em núcleo de favela, integrante do grupo focal, em dezembro de 2015.

II Disponível em: https://www.terra.com.br/vida-e-estilo/moda/gloria-pires-domina-lista-de-figurinos-mais-pedidos-da-globo,4354e0 I b0debc4 I OVgnVCM4000009bcceb0aRCRD.html. 
de Glória, feito pelo profissional Márcio Mello, foi o mais pedido entre as telespectadoras em março (GLÓRIA, 2015, [s. p.]). ${ }^{12}$

A referência ao universo das celebridades como modelo desejável e inalcançável foi uma constante nas conversas estabelecidas; contudo, ao remetermos para as consumidoras "reais", que frequentam o shopping e consomem as "roupas de marca", a reação era oposta: desdém recheado de ironia, revelado nas imitaçóes dos trejeitos típicos das "patricinhas" ou "boyzinhas", como elas definiam.

Além das personagens de telenovela, o universo do futebol também se configura em um significativo fornecedor de modelos e estilos. Em uma das dinâmicas experimentadas no grupo focal, foram apresentados, em cartôes, os logos de várias grifes e aqueles ligados ao esporte (Puma, Nike, Adidas) foram os mais reconhecidos. Estas marcas, diretamente relacionadas ao universo internacionalizado do futebol, associam-se à boa parte dos ídolos populares e contam com muita exposição na mídia.

Contudo, como apontado em outros momentos (CASTRO; PRADO, 2012), partimos do pressuposto de que os modelos fornecidos pela mídia e pelo mercado sáo incorporados de maneiras diversas e de que os sentidos desta incorporação nem sempre implicam imitar para assemelharse. A perspectiva analítica proposta pela teoria das mediaçóes MARTÍNBARBERO, 1997; CANCLINI, 1997; THOMPSON, 1995, 1998), pressupóe uma relação de dupla mão entre os polos da produção e da recepção das mensagens midiáticas, na qual os conteúdos veiculados dialogam diretamente com o cotidiano dos expectadores/leitores, e estes (re) significam as mensagens a partir de suas experiências e repertórios. Nesta linha, portanto, recomenda-se que a análise das mensagens atente para as matrizes culturais acionadas pelos gêneros ficcionais em questáo; no caso das telenovelas, por exemplo, o melodrama e sua tríade essencial de personagens (vilão, vítima e herói) - presente no entretenimento popular desde as encenaçóes das trupes teatrais itinerantes no século XVIII, passando pela radionovela, fotonovela, até chegar ao formato cultural atual - é a

12 http://www.purepeople.com.br/noticia/gloria-pires-de-babilonia-lidera-ranking-de-pedidos-da-globo-veja-a-lista_a551 |4/1. 
principal referência (MARTÍN-BARBERO, 1997). Em outras palavras, o processo de comunicação não pode ser compreendido como apenas imposto, de cima para baixo, sem o acionamento de códigos culturais que dialoguem com os esquemas culturais (SAHLINS, 2004) reconhecíveis pelos receptores.

Nessa mesma linha, Thompson (1995) salienta que os meios de comunicação criam novas formas de ação e interação entre os indivíduos e novos tipos de relaçóes sociais, permitindo a interação sem o compartilhamento do mesmo contexto tempo-espacial. Essa "interação quase mediada” - relaçóes sociais estabelecidas pelos meios de comunicação de massa (livros, jornais, revistas, televisão etc.) - também classificada como quase interação, é diferente dos outros tipos de interação por ser monológica, ou seja, o fluxo da comunicação assume um sentido único, configurando receptores de formas simbólicas cujo remetente náo recebe uma resposta imediata. Esse tipo de interação cria "[...] certo tipo de situação social na qual os indivíduos se ligam uns aos outros num processo de comunicação e intercâmbio simbólico" (THOMPSON, 1995, p. 80).

As mensagens, ou formas simbólicas, como denomina Thompson, estâo sempre inseridas dentro de contextos sociais estruturados, sendo produzidas por agentes situados dentro de um contexto sócio-histórico específico e recebidas por indivíduos que também estão situados em seus respectivos contextos sócio-históricos e dotados de determinados recursos. Segundo o autor "[...] o modo como uma forma simbólica particular é compreendida por indivíduos pode depender dos recursos e capacidades que eles são aptos a empregar no processo de interpretá-la” (THOMPSON, 1995, p. 193). Assim, em consonância com a teoria das mediaçóes proposta por Martín-Barbero (1997), Thompson afirma a necessidade de estar atento aos contextos sociais em que as mensagens são recebidas. Qualquer reflexão sobre a recepção das mensagens da mídia deve entendê-la como um processo contínuo e socialmente diferenciado, “[...] que depende do conteúdo das mensagens recebidas, da elaboração discursiva das mensagens entre os receptores e os outros e dos atributos sociais dos indivíduos que as recebem" (THOMPSON, 1995, p. 201).

Buscamos, nesse sentido, situar os discursos dos interlocutores participantes do grupo focal, considerando o contexto e os atributos sociais que 
os marcam: jovens que não ingressaram e nem cogitam ingressar na universidade, moradores da periferia, integrantes de famílias de baixa renda. Seus discursos revelam, no que diz respeito à relação com o universo das marcas esportivas, certa ambiguidade: ao mesmo tempo em que buscam pelo distanciamento do que é considerado "supérfluo" e associado a grupos sociais que são ridicularizados - aos quais se atribui uma imagem negativa - também manifestam o desejo por apropriar-se daquilo, quando remetido ao glamoroso universo dos personagens das telenovelas e campeóes esportivos.

Como apontou Martín-Barbero (1997), apoiando-se em Morin (1987), os mecanismos de "projeção e identificação" são os principais pilares das "estratégias de comunicabilidade" operadas pelos meios de comunicação. Nas palavras do autor, as "[...] estratégias de comunicabilidade são os modos em que se fazem reconhecíveis e organizam a competência comunicativa os emissores e os destinatários" (MARTÍN-BARBERO, 1997, p. 302). Como mecanismos principais destas estratégias de penetração no universo cotidiano do leitor/expectador, temos, de um lado, situações e personagens que promovem a "identificação" com a dimensão humana, compartilhada universalmente, que sente prazer ao perceber que seus sofrimentos, crises, satisfaçóes e alegrias também são vivenciados pelos seus ídolos. De outro lado, situaçóes que remetem ao universo do sonho e da fantasia, do inalcançável, permitindo a evasão, o deslocamento do aqui e agora, resultantes da possibilidade "de projeção" acionada pela mídia.

As potências de projeção - isto é, também as de divertimento, de evasão, de compensação, de expulsão [...] - se propagam por todos os horizontes do imaginário [...] atiram-se nos alhures do tempo e do espaço, regiões exóticas ou passados fabulosos [...] Divertem-se nos universos idealizados, onde tudo é mais intenso, mais forte, melhor. No meio de todas essas projeções, funciona uma certa identificação: o leitor ou expectador, ao mesmo tempo em que libera fora dele virtualidades psíquicas, fixando-as sobre heróis em questão, identifica-se com personagens que, no entanto, lhe são estranhas e se sente vivendo experiências que, contudo, não pratica. (MORIN, 1987, p. 82).

Diante do exposto, podemos afirmar que o desejo de apropriação das marcas por parte dos nossos interlocutores se articula menos à elaboração de identificações com "os de cima", e mais com o mecanismo de projeção. Tudo indica que, quando aplicada "à vida como ela é", a aquisição desses "bens de marca", quando ocorre, remete ao que Bourdieu (1996?) 
denominou de "senso prático", para caracterizar o ethos popular, revelado em expressões como: "compro para ser melhor aceito no ambiente de trabalho"13, ou "quando posso compro, porque dura mais" 14 . Cabe ressaltar que, ao tomarmos os discursos, consideramos a dimensão inconsciente da incorporação do habitus (Bourdieu 2007), expressa pelas práticas dos agentes. Nosso interesse, neste caso, é apenas evidenciar o reconhecimento de uma lógica distintiva - que opera predominantemente - e as formas de apropriação e ressignificação dessa lógica por grupos que não participam da definição dos códigos que a regem. Como ilustração, a seguir, expomos um fragmento do diário de campo, no qual descrevemos a imitação de um desfile de moda improvisado, ocorrido no galpão da Associação de Moradores, em um dos bazares organizados para comercializar algumas roupas e acessórios doados. Havia um cesto grande, de plástico, com várias roupas e acessórios, como óculos e bolsas usados em bom estado, muitos deles de grifes famosas. Duas jovens moradoras, em tom irônico, recolheram algumas peças para experimentar e ao saírem vestidas, imitaram modelos profissionais desfilando, exagerando nos gestos, de forma caricatural, enquanto os demais gargalhavam $[\ldots] .{ }^{15}$

Neste episódio foi evidente a ridicularização, traduzida pelos gestos caricaturais associados às garotas pertencentes a outro grupo social, identificadas como "patricinhas" ou "boyzinhas".

Conforme aponta Simmel (2008), em suas reflexôes sobre a moda, os estilos adotados pelas elites aos poucos se difundem para os mais pobres, com a intermediação das classes médias. Nesse sentido, os indivíduos da periferia consumiriam as grifes para imitar as classes superiores, o que, de fato, identificamos em nossa pesquisa.

E, quando perguntamos se alguma vez efetivamente compraram uma roupa de marca original e por qual motivo o fizeram, as respostas foram:

"Porque era original e só as patricinhas tinham. Eu morava aqui na comunidade [...]. Eu também podia ter. Só porque eu morava na comunidade que eu não ia ter? Porque só quem tinha mais era as boyzinhas". ${ }^{6}$

13 Depoimento de Nora, estudante do segundo ano do ensino médio, 27 anos, recepcionista, concedido em entrevista individual em abril de 2014.

14 Flávia, estudante do primeiro ano do ensino médio, 20 anos, balconista em loja do bairro, integrante do grupo focal, em dezembro de 2015.

15 Trecho extraído do diário de campo, 30 de novembro de 2014.

16 Depoimento de Maria, 23 anos, dona de casa, concedido a esta pesquisa durante grupo focal em dezembro de 2015. 
"A minha história é quase igual a dela. Comprei no shopping. Se elas podem, eu também posso. Foi a mesma sensação dela. Me senti patricinha um dia". ${ }^{17}$

Contudo, percebemos que "o sentido das apropriações" não é o de buscar imitar para parecer com as classes médias, mas, de certo modo, brincar com elementos de seu universo, permanecendo em seu próprio. Aproximamo-nos, nesse momento, de outras pesquisas que trabalharam com recortes empíricos na periferia de grandes cidades, como o de Mizrahi (2014), que enfatizou a agência dos sujeitos, ao perceber o sentido próprio atribuído, em contextos locais, à apropriação de elementos pertencentes a outros domínios culturais

Enfim, é possível perceber que o discurso sobre a compra de marcas originais e réplicas para exibição de símbolos não carrega, necessariamente, o sentido de imitação como estratégia de assumir outra posição no campo social ou pertença a classes mais abastadas. Em sintonia com o que já haviam identificado Scalco e Pinheiro Machado (2010), podemos sugerir como uma boa hipótese para trabalhos futuros, que se voltem à compreensão dos sentidos do consumo, que o desejo de distinção consiste em um dos sentidos atribuídos ao consumo, dentre tantos outros a serem desvendados. Além disso, há que se considerar que, dentre grupos de baixa renda, a busca de distinção pode ser observada, sobretudo, "intraclasse" e não "extraclasse".

\section{Referências}

BRASIL. Secretaria de Assuntos Estratégicos. Natureza e dinâmica das mudanças recentes na renda e na estrutura ocupacional brasileiras. Comunicados IPEA, no 104, agosto/2011. Disponível em: http://portal.mte.gov.br/data/files/8A7C812D3374524E013389E20D294A08/IPEA_110804_ comunicadoipea104.pdf. Acesso: 13 jul. 2015.

BRASIL. Secretaria de Assuntos Estratégicos. Cartilha Vozes da Classe Média. Brasília, DF: 2012. Disponível em: www.sae.gov.br/wp-content/uploads/Cartilha-Vozes-Classe-Media.pdf. Acesso em: 10 fev. 2019.

ADORNO, T.; HORKHEIMER, M. Dialética do esclarecimento. Rio de Janeiro: Zahar, 1985.

17 Depoimento de Joana, 24 anos, cabeleireira, concedido a esta pesquisa durante grupo focal em dezembro de 2015. 
ALVES, J. E. D.; CAVENAGHI, S. Tendências demográficas, dos domicílios e das famílias no Brasil. Aparte: Inclusão Social em Debate, 24 ago. 2012. Disponível em http://www.ie.ufrj.br/ aparte/pdfs/tendencias_demograficas_e_de_familia_24ago12.pdf. Acesso: 21 de fev. 2019.

APPADURAI, A. Dimensóes culturais da globalizaçáo. Lisboa: Ed. Teorema, 2004.

APPADURAI, A. A vida social das coisas. Rio de Janeiro: Ed. UFF, 2008.

BAUDRILLARD, J. Sociedade de consumo. Lisboa: Edições 70, 1985.

BOURDIEU, P. Razóes práticas: sobre a teoria da ação. Tradução Mariza Corrêa. Campinas, SP: Papirus, 1996

BOURDIEU, P. A distinção: crítica social do julgamento. São Paulo: EDUSP; Porto Alegre: Zouk, 2007.

CANCLINI, N. G. Culturas híbridas. São Paulo: EDUSP, 1997.

CASTRO, A. L. de. Sentidos do consumo e fronteiras simbólicas: uma etnografia entre grupos de baixa renda em um município da Grande São Paulo, Brasil. Etnográfica, Lisboa, v. 20, n. 1, p. 101-117, 2016.

CASTRO, A. L. de; PRADO, J. do. Corpo e identidades femininas: a intermediação da mídia. Revista Estudos de sociologia, Araraquara, v. 17, n. 32, p. 241-259, 2012.

CERTEAU, M. de. A invençáo do cotidiano: artes de fazer. Vol. 1. Petrópolis: Vozes, 1994.

DOUGLAS, M.; ISHWWOOD, B. O mundo dos bens: para uma antropologia do consumo. Rio de Janeiro: Ed. UFRJ, 2004.

DUARTE, A. A antropologia e o estudo do consumo: revisão crítica de suas relações e possibilidades. Etnográfica - Revista do Centro em Rede de Investigação em Antropologia, v. 14, n. 2, p. 363393, 2010.

DUARTE, L. F. Da vida nervosa das classes trabalhadoras urbanas. Rio de Janeiro: Zahar Ed. 1986.

FEATHERSTONE, M. Cultura de consumo e pós-modernismo. São Paulo: Studio Nobel, 1995.

FONSECA, C. Família, fofoca e honra. Porto Alegre: Editora da UFRGS, 2000.

GLÓRIA Pires, de «Babilônia`, lidera ranking de pedidos da Globo. Veja a lista!. Purepeople, 11 maio 2015. http://www.purepeople.com.br/noticia/gloria-pires-de-babilonia-lidera-ranking-depedidos-da-globo-veja-a-lista_a55114/1. Acesso em 15 fev. de 2019

HOGGART, R. As utilizaçóes da cultura. Lisboa: Editorial Presença, 1973.

MARTÍN-BARBERO, J. Dos meios às mediaçóes: comunicação, cultura e hegemonia. Rio de Janeiro: Ed. UFRJ, 1997.

MAUSS, M. Ensaio sobre a dádiva. Forma e razão da troca nas sociedades arcaicas. In: MAUSS, M. Sociologia e Antropologia. São Paulo: Cosac \& Naify, 2003. p.? 
MILLER, D. Teoria das compras: o que orienta as escolhas dos consumidores. São Paulo: Nobel, 2002 .

MILLER, D. Pobreza da moralidade. Antropolítica: Revista Contemporânea de Antropologia e Ciência Política, n. 17, p. 21-43, 2o sem. 2004.

MIZRAHI, M. A estética funkcarioca: criação e conectividade em Mr. Catra. Rio de Janeiro: 7 Letras, 2014.

NÉRY, M, A nova classe média:o lado brilhante da base da pirâmide .São Paulo: Saraiva, 2011.

SAHLINS, M. Cosmologias do capitalismo: o setor transpacífico do "sistema Mundial". In: SAHLINS, M. Cultura na prática. Rio de Janeiro: Ed. UFRJ, 2004. p. 443-486.

SARTI, C. A família como espelho: um estudo sobre a moral dos pobres. Campinas: Ed. Autores associados/FAPESP, 1996.

SCALCO, L. M.; PINHEIRO-MACHADO, R. Os sentidos do real e do falso: o consumo popular em perspectiva etnográfica. Revista de Antropologia, São Paulo, v. 53, n. 1, p. 321-359, 2010.

SOUZA, J. Os batalhadores brasileiros: nova classe média ou nova classe trabalhadora?. Belo Horizonte: Editora UFMG, 2010.

SIMMEL, G. Questóes fundamentais de sociologia: indivíduo e sociedade. Rio de Janeiro: Zahar, 2006.

SIMMEL, G. Filosofia da Moda e outros ensaios. Lisboa: Ed. Texto e Grafia, 2008.

THOMPSON, J. B. Ideologia e cultura moderna: teoria social crítica na era dos meios de comunicação de massa. Petrópolis: Vozes, 1995.

THOMPSON, J. B. A mídia e a modernidade: uma teoria social da mídia. Petrópolis: Vozes, 1998.

VEBLEN, T. A teoria da classe ociosa: um estudo econômico das instituiçóes. São Paulo: Abril Cultural, 1983. (Coleção Os economistas).

ZWIPP, P. Glória Pires domina lista de figurinos mais pedidos da Globo. Terra, 15 abr. 2015. Disponível em: https://www.terra.com.br/vida-e-estilo/moda/gloria-pires-domina-lista-defigurinos-mais-pedidos-da-globo, $4354 \mathrm{e} 01 \mathrm{~b} 0 \mathrm{deb} 410 \mathrm{VgnVCM} 4000009 \mathrm{bcceb} 0 \mathrm{aRCRD}$.html. Acesso em 15 fev. de 2019.??

Recebido: 25/03/2019

Aceito: 08/11/2019 


\section{Media and market: mediations in the construction of meanings of the consumption of "branded clothes"}

\section{Abstract}

Taking as an empirical universe a neighborhood located in the outskirts of Santo André, city of the metropolitan region of São Paulo, this article seeks to contribute to the understanding of the symbolic dimension of consumer goods and the meanings attributed to them in peripheral contexts. Specifically, we approached the relationship with the universe of designer brands, or, in the words of the interlocutors, branded clothes, starting from conversations conducted during a focus group with young people ( 18 to 24 years old), as well as some excerpts from individual interviews. and field notebook records. It also discusses the role of guiding guidance by the media, disseminating styles of clothing and accessories, as well as brands, especially sports. We are interested in identifying the modes of appropriation and use, as well as motivations for consumption - beyond practical-utilitarian reasons - by discussing the relevance of the hegemonic sociological explanation, which points to the logic of imitation-distinction as main motivator for this practice (VEBLEN, 1983; SIMMEL, 2006; BOURDIEU, 2007).

Keywords: consumption, media, mediations, social distinction, modes of use. 